\title{
Under the influence of the environment: children's responding invigorated and biased by predictive cues
}

\author{
Daniel E. Alarcón ${ }^{1,2}$ \& Charlotte Bonardi ${ }^{1}$ \\ ${ }^{1}$ School of Psychology, University of Nottingham, University Park, Nottingham NG7 2RD, \\ United Kingdom \\ 2 Present address: Departamento de Psicología, Universidad de Chile, Av. Ignacio Carrera \\ Pinto 1045, Santiago, Chile
}

Declaration of interest: None

Word count: 7827

The elaboration of this manuscript was supported by a postdoctoral grant awarded by Conicyt (Fondecyt \# 3170166) to Daniel E. Alarcón.

Corresponding Author:

Daniel E. Alarcón

Av. Capitán Ignacio Carrera Pinto №1045

Santiago, Chile

Phone: +56 229787784

E-mail: dealarcon@u.uchile.cl 


\begin{abstract}
Cues that signal motivationally significant consequences can elevate responding and bias choice. A task known as Pavlovian-to-instrumental transfer (PIT) has been used to assess the influence of these cues on independently trained responses, and to study the effect of drug-related and food-related cues on behavior in adult populations, but has not yet been employed in children. This study aimed to develop a simple computer task to study PIT in children. Participants, aged between 7 and 11 years, observed a screen in which different pairings of distinct cartoon images and specific outcomes were presented (images of foods/drinks in Experiment 1, and images of pets in Experiment 2). After this, the participants pressed two keys, each consistently reinforced with one of the two outcomes. Finally, the children pressed both keys in the absence of any outcome, and each cartoon image was presented periodically so that the effect of these cues on behavior could be measured. Experiment 1 showed that the cartoons' presentations biased responding towards the key that was trained with the same outcome as the cartoon being presented, i.e. outcome-specific PIT. Experiment 2 replicated this finding, and also showed that a cartoon trained with an outcome different to those reinforcing the responses elevated performance of both responses, relative to a cartoon that was not paired with any outcome in training, i.e. general PIT. These findings are consistent with those reported in the adult population, and might be a useful tool to study the early development of maladaptive behaviors.
\end{abstract}

Keywords: learning; behavior; Pavlovian-to-instrumental transfer; motivation; eating; choice 


\section{Introduction}

Research has consistently shown that a stimulus (S) that signals the delivery of a motivationally significant outcome $(\mathrm{O})$, such as food, can acquire motivational properties similar to those of the consequence it predicts, granting it the ability to influence behavior in different manners (Boakes, 1979; Konorski, 1967; Robinson \& Berridge, 1993). For instance, cues that have been paired with food, such as its smell, taste, or even the context in which the food was consumed, can elicit physiological responses similar to those produced by the food itself (Jansen et al., 2003; Nederkoorn, Smulders, \& Jansen, 2000; Rodin, 1985; Wardle, 1990). But these cues can also invigorate or reduce responses that earn motivationally significant outcomes (e.g., Bindra, 1968), meaning they are capable of biasing choice. This effect on responding has been studied by using the Pavlovian-to-instrumental transfer (PIT) procedure, which has three components: Pavlovian conditioning, instrumental training, and a PIT test. In the Pavlovian conditioning phase predictive relationships between cues are established by presenting one or more cues, usually neutral images, each followed by a distinct outcome. These outcomes can be rewards such as foods or drinks, but can also be symbolic, such as images of foods, drinks, money, etc. In the instrumental phase one or more responses are each reinforced with one of the outcomes; for instance, pressing a particular key is rewarded by the presentation of a food image and a different key by a drink image. At test, participants are allowed to perform the instrumental response(s) in the presence and absence of each of the Pavlovian cues and the effect that these cues exert on performance is measured (for a review see Holmes, Marchand \& Coutureau, 2010), which is thought to reflect to the Pavlovian properties of the stimuli (see Dickinson \& Balleine, 2002).

Researchers using this type of task have reported that PIT can take two different forms. In the outcome-specific form, stimulus presentations at test bias choice by 
selectively elevating performance of a response trained with the same outcome as the stimulus, relative to a response trained with a different outcome. For instance, if two responses are trained, one with chocolate and the other with popcorn, an elevation in the response trained with chocolate is found if the stimulus presented was also trained with chocolate, but not if the stimulus was trained with popcorn (and the opposite for the response trained with popcorn). However, if a stimulus signals an outcome different to those used to train the instrumental responses, this stimulus will also invigorate responding but regardless of the identity of the reinforcers (general PIT). For instance, if a stimulus was trained with nuts, this stimulus elevates both the response trained with chocolate and the response trained with popcorn (Watson, Wiers, Hommel \& de Wit, 2014). While the general PIT effect can be explained by a non-selective motivational effect on behavior elicited by the stimulus (cf. Rescorla \& Solomon, 1967), the selectivity of the outcome-specific PIT effect can only be explained by a mechanism that encodes the sensory aspects of the outcome (cf. Trapold \& Overmier, 1972).

The PIT effect has been extensively reported in human and non-human animal studies (e.g., Alarcón \& Bonardi, 2016; Alarcón, Bonardi \& Delamater, 2017; Colwill \& Rescorla, 1988; Delamater, 1996; Holland, 2004; Kruse, Overmier, Konz \& Rokke, 1983), and it has been related to a number of different phenomena such as drug addiction, overeating, stress, schizophrenia, and depression, among others (e.g., Alarcón \& Delamater, 2019; Colagiuri \& Lovibond, 2015; Garbusow et al., 2016; Lamb, Ginsburg \& Schindler, 2017; Morris et al., 2015; Quezada, Alarcón, Miguez \& Betancourt, 2011; Quail, Morris \& Balleine, 2017; Watson et al., 2014). Although PIT has proved a versatile task that yields robust effects, it has only been used to study adults and there are as yet no studies exploring the effect in the child population. Although one might assume that children will show both outcome-specific and general PIT exactly as adults do, this is not 
necessarily the case, as there is a substantial literature suggesting that children have difficulties in some learning tasks. For example, adults outperform children in choice-tasks (e.g., pressing right and left keys) in which feedback is important: children learn at a lower rate than both adolescents and adults (Hämmerer, Li, Müller \& Lindenberger, 2010), they are not as good as adults at identifying relevant feedback (Crone, Jennings \& Van der Molen, 2004), and they are less accurate than adults when feedback is not entirely consistent (Eppinger, Mock \& Kray, 2009). Moreover, there are a number of reports that both children and adolescents are worse than adults in acquiring classically conditioned discriminations, between one stimulus that predicts an aversive outcome and another that does not (Glenn et al., 2011; Jovanovic et el., 2014; Lau et al., 2011; Waters et al., 2017; although others have not reported differences: Craske et al., 2008; Liberman, Lipp, Spence, \& March, 2006; Neumann, Waters, Westbury, \& Henry, 2008b; Waters, Henry, \& Neumann, 2009). Although it is not clear how these specific differences might affect the observation of PIT, they do suggest it might not be safe to assume that children will perform like adults on all learning tasks. Thus, given the potential importance of PIT for clinical studies, it is important to demonstrate the effect in young people. If children do show PIT like adults, this task could be used to study maladaptive behavior from an earlier age; in the case of overeating, for instance, one important factor is the influence of environmental cues on eating. To find a simple tool to study the effect of these cues becomes critical, especially considering that overeating during childhood is highly correlated with obesity in adulthood (Deckelbaum \& Williams, 2001).

One interesting aspect of PIT research is the diversity of outcomes used in these studies. In animal PIT studies, caloric stimuli such as food pellets or sugared solutions can be used as outcomes. Similarly, in some human studies valuable outcomes (e.g., snacks, money, cigarettes puffs) are delivered either during or at the end of the task. However, 
some human research has used symbolic rewards (e.g., fictitious currency, neutral images, pictures of foods or drinks). The use of discrete symbolic outcomes allows the researcher to better manipulate the temporal aspects of the relations being studied, but more importantly provides evidence that a cue does not necessarily need to be directly paired with a valuable consequence to affect behavior. This is critical, considering the effect that daily environmental stimuli have on our behavior, for instance, advertising in the streets, supermarkets, or publicity transmitted on television and internet in the form of commercials, product placement, or in video games.

Here we report the results of two PIT experiments conducted in children aged between 7 and 11 years old. Similar age groups have been used in the studies mentioned above in which the rate of learning was compared between children and adults (Crone et al., 2004; Eppinger et al., 2009; Hämmerer et al., 2010). The aim of Experiment 1 was to assess if outcome-specific PIT is found in child participants, while the aim of Experiment 2 was to extend the scope of the study by assessing outcome-specific and general PIT effects in the same task. In addition, the goal of both experiments was to demonstrate PIT using symbolic rather than real outcomes. Experiment 1 aimed to replicate the effect using images of foods and drinks, which are the traditional outcomes used in this type of task. In Experiment 2, the generality of the PIT effects was assessed by using images of pets.

\section{Experiment 1: Outcome-specific PIT}

The task was a computer game consisting of a Pavlovian conditioning phase, an instrumental training phase, and a PIT test (see Table 1). In the Pavlovian phase, presentations of different neutral stimuli (cartoon images of children; $S_{1}, S_{2}$ and $S_{3}$ ) were each paired with presentations of either a particular outcome (images of foods or drinks;

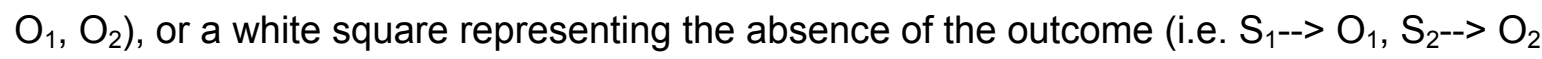
and $S_{3^{--}}$no outcome). In the instrumental training phase, pressing one key $\left(R_{1}\right)$ was 
rewarded with one of the outcomes $\left(\mathrm{O}_{1}\right)$, while pressing a different key $\left(\mathrm{R}_{2}\right)$ was rewarded with the alternative outcome $\left(\mathrm{O}_{2}\right)$. In the test, participants had the chance to perform both responses $\left(R_{1}\right.$ and $\left.R_{2}\right)$ in the presence and absence of the neutral stimuli. If PIT is also found in children, then presentations of $S_{1}$ and $S_{2}$ at test should elevate responding relative to $S_{3}$. Furthermore, if this effect is outcome-specific, then $S_{1}$ and $S_{2}$ should selectively elevate a specific response depending on the outcome it had earned; specifically presentations of $S_{1}$ should elevate $R_{1}$ more than $R_{2}$, while presentations of $S_{2}$ should elevate $R_{2}$ more than $R_{1}$. In contrast, the control stimulus $S_{3}$ should produce no change in responding. After the test, and to assess that participants were paying attention throughout the task, they were asked to identify each of the S-O relationships.

Table 1. Design of Experiment 1.

\begin{tabular}{llll}
\hline Pavlovian Phase & Instrumental Phase & PIT Test & Rating Stage \\
\hline $\mathrm{S}_{1}>\mathrm{O}_{1}$ & $\mathrm{R}_{1}->\mathrm{O}_{1}$ & $\mathrm{~S}_{1}: \mathrm{R}_{1}$ ? $\mathrm{R}_{2} ?$ & $\mathrm{~S}_{1}: \mathrm{O}_{1}$ or $\mathrm{O}_{2} ?$ \\
$\mathrm{~S}_{2^{-}}>\mathrm{O}_{2}$ & $\mathrm{R}_{2^{-}>\mathrm{O}_{2}}$ & $\mathrm{~S}_{2}: \mathrm{R}_{1}$ ? $\mathrm{R}_{2} ?$ & $\mathrm{~S}_{2}: \mathrm{O}_{1}$ or $\mathrm{O}_{2} ?$ \\
$\mathrm{~S}_{3^{-}}$ & & $\mathrm{S}_{3}: \mathrm{R}_{1}$ ? $\mathrm{R}_{2} ?$ & $\mathrm{~S}_{3}: \mathrm{O}_{1}$ or $\mathrm{O}_{2} ?$ \\
\hline
\end{tabular}

Note: $R_{1}$ and $R_{2}$ refer to keyboard responses; $S_{1}, S_{2}$, and $S_{3}$ refer to neutral cartoon images of children; $\mathrm{O}_{1}$ and $\mathrm{O}_{2}$ refer to food and drink images.

\section{Method}

\section{Participants}

Twelve children aged between 7 and 10 years ( 6 males and 6 females) participated in this experiment. The participants were attending Summer Scientist Week (www.summerscientist.org), an event organized by the University of Nottingham in which families visit the University, and their children participate in different research studies.

\section{Ethics statement}


The studies reported here, their procedures and consent forms were approved by the School of Psychology Ethics Committee of the University of Nottingham. Participants' parents or carers gave informed consents for their children to participate in the studies conducted in the Summer Scientist Week, and all the participants gave verbal consent before participating in the task.

\section{Apparatus and materials}

The experiment was programmed in PsychoPy (Peirce, 2007), and conducted on a computer with a 15.4 inch screen. The screen showed general instructions at the beginning of the task, and specific instructions before each phase. Three cartoon images of children were used as $S s\left(S_{1}, S_{2}\right.$ and $\left.S_{3}\right)$, and 16 pictures of foods and drinks (8 of each) were used as outcomes (see Figure 1). All the images were $100 \times 100 \mathrm{~mm}$ in size. On the non-reinforced trials, a white square image $(100 \times 100 \mathrm{~mm})$ was used as the outcome. Each S, when presented, was located either to the left or right side of the screen (100 $\mathrm{mm}$ from the centre), and each outcome image was positioned at the centre of the screen. Each Pavlovian trial began with a black fixation dot at the centre of the screen $(3 \mathrm{x}$ $3 \mathrm{~mm})$, which was replaced by a black fixation cross $(10 \times 10 \mathrm{~mm})$ in the instrumental training phase and PIT test. The instrumental responses consisted of pressing the keys ' $z$ ' and 'm', which were covered with a red sticker to highlight their position. Pressing the left key ('z') was reinforced with drink images and the right key ('m') with food images. The space bar was used to start each of the phases, after the instructions were read, and it was marked with green stickers. The identities of $S_{1}, S_{2}$ and $S_{3}$ were fully counterbalanced, resulting in 6 counterbalanced subgroups. For half of each of these subgroups $\mathrm{O}_{1}$ was a drink image and $\mathrm{O}_{2}$ a food image, and the reverse for the remainder, resulting in a total of 12 counterbalanced subgroups with one participant in each (see supplementary materials). 

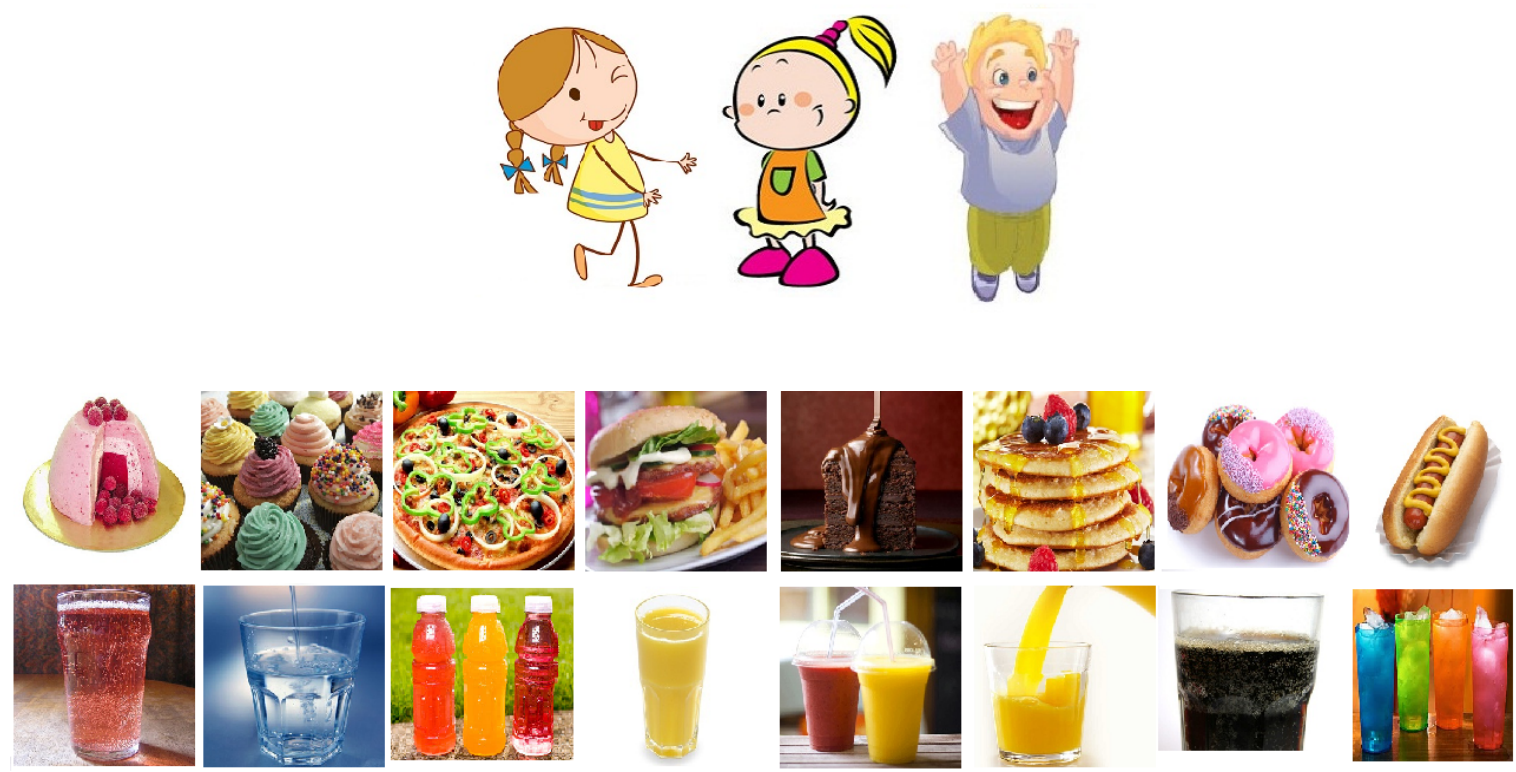

Figure 1. Neutral stimuli and outcomes used in Experiment 1

\section{Procedure}

Participants were walked to a room in which the experiments were conducted, and they were seated in front of a computer. Then they received general instructions orally from the researcher, and then they were asked to read out loud the following specific instructions before continuing with each of the experimental phases.

\section{Pavlovian phase}

Participants read the following instructions:

"Now you will see some children. Some of them will get food, some will get drinks and some will get nothing.

Are you ready to find out which child gets which reward??

When you are ready press the green button"

Each trial began with the fixation dot, which remained on the screen for 2 seconds. After this, an $\mathrm{S}$ was presented on either the left or right side of the screen, and 2 seconds 
later the corresponding outcome appeared next to the $S$ (in the centre of the screen). After 2 additional seconds the $S$ and the outcome were replaced by the fixation dot, starting a new trial. This phase was divided into four blocks, each of them comprising two trials of each of the following trial types: $\mathrm{S}_{1}->\mathrm{O}_{1}, \mathrm{~S}_{2}->\mathrm{O}_{2}$, and $\mathrm{S}_{3}->$ nothing presented in a semirandom order (8 trials of each type in total).

\section{Instrumental training phase}

Participants read the following instructions:

"Now press the red keys to see food and drink pictures!

One key will produce food pictures, and the other drink pictures. You must get 30 of each but sometimes the pictures won't appear, so you must keep pressing!

When you are ready press the green button"

The fixation cross was present throughout this phase, except when an outcome image was delivered. Each of the responses was reinforced according to a variable ratio 3 schedule (VR 3); for example, after an average of $3 R_{1}$ responses an $O_{1}$ was presented on the screen; $\mathrm{R}_{2}$ responses were followed by presentations of $\mathrm{O}_{2}$ according to the same schedule. Each of the outcome presentations lasted 0.8 seconds. If participants pressed either ' $z$ ' or ' $m$ ' during the outcome presentation, that outcome image was immediately replaced by the fixation cross. Two counters showing the exact number of outcomes earned at any given time were positioned at the top corners of the screen, each incrementing by one every time the corresponding outcome was delivered. The text "Drink $="$ in orange letters, together with the number of drink images obtained by the participant, was displayed in the left corner, while in the right corner the text "Food = " in blue letters, 
together with the corresponding number of earned food images, was displayed. This phase ended when participants had obtained at least 30 outcomes of each type.

\section{PIT test}

Participants read the following instructions:

"Now it's time to press the red keys again to get food and drink pictures.

You will not see the food and drink pictures you are getting, so you must keep pressing!

When you are ready press the green button"

In this test participants could perform $\mathrm{R}_{1}$ and $\mathrm{R}_{2}$ as much as they wanted, but no outcomes were delivered. The test began with the fixation cross alone on the screen, which remained present throughout the entire test. Each of the trials comprised a 2-sec pre-S baseline period, in which only the cross was present, after which an S appeared either on the left or right side of this cross (S period). The $S$ remained on the screen for 4 seconds, and was then replaced by the cross alone for an additional 1 second (intertrial interval: ITI). The next trial then commenced immediately. The food and drink counters used in the instrumental training phase remained on the screen in this phase, but the symbol "?" replaced the numbers that had indicated the number of outcomes earned in the previous phase. This test was divided into 2 blocks, each of them consisting of 2 trials each of $S_{1}, S_{2}$, and $S_{3}$ presented in a semi-random order (4 trials per type in total); the number of $R_{1}$ and $R_{2}$ responses performed in the pre-S and $S$ periods was recorded.

\section{Rating Stage}

Participants read the following instructions: 
"Now you will see the children again. Can you remember which child got which reward?

If they got a drink, click the line near the DRINK picture. If they got food, click the line near the FOOD picture. If they got nothing, click the line in the middle.

When you are ready press the green button"

In each of the trials the text "What did this child get?" was located at the top of the screen with the corresponding $S$ image below it, and a visual rating scale at the bottom of the screen. A drink image together with the word "Drink" in orange letters was presented on the left of the scale, and on the right a food image and the word "Food" in blue letters. On each trial different food and drink images were used, $3 \times 3 \mathrm{~cm}$ in size, selected from the group of images used in the previous phases. This test was divided into 2 blocks, each comprising one trial each of $\mathrm{S}_{1}, \mathrm{~S}_{2}$, and $\mathrm{S}_{3}$.

\section{Data treatment}

The data were analysed using analysis of variance (ANOVA), and sets of orthogonal contrasts were used to further analyse significant differences. Partial etasquared $\left(\eta_{p}{ }^{2}\right)$ and its $90 \%$ confidence interval were given for significant effects and interactions. The responses made during the PIT tests were transformed to responses per minute (rpm). Then, to reveal any elevation of instrumental responding produced by the various Ss, PIT scores were calculated for each response and each S type, by subtracting response rates during the pre-stimulus period from responding during the $S$ presentation that followed it. Finally, these PIT scores were grouped as 'same' and 'different', depending on whether the outcome that previously reinforced the response matched that signaled by the $S$. Thus $R_{1}$ responses during $S_{1}$, and $R_{2}$ responses during $S_{2}$, were 
grouped as 'same', while $R_{2}$ responses during $S_{1}$ and $R_{1}$ responses during $S_{2}$ were grouped as 'different'. PIT scores for responding during the Ss that did not signal any outcome $\left(\mathrm{S}_{3}\right.$ in Experiment 1 and $\mathrm{S}_{4}$ in Experiment 2) were collapsed and grouped as 'control'. Positive scores reflected an elevation on instrumental responding during the stimuli presentations, while negative scores a reduction. One-sample two-tailed t-tests were conducted to assess if these scores significantly differed from zero. In the rating stage, each position on the scale provided a value from 0 , left of the scale, to 1 , right of the scale ("nothing", in the middle of the scale, was 0.5 ). Scores for each trial were calculated by subtracting participants' responses on the scale from the expected response, such that a value of 0 represented a correct answer. A learning criterion based on the rating scores was defined to exclude those participants that did not learn the associations; however, all of them answered all the questions virtually correctly (see below).

\section{Results}

All participants obtained 30 outcomes of each type in the instrumental training phase. The results of interest from the PIT test are presented in Figure 2. It is clear from the figure that S presentations elevated instrumental responses trained with the same outcome as the $S$ (Same; i.e. $R_{1}$ during $S_{1}$ and $R_{2}$ during $S_{2}$ ), relative to the $S$ that signaled the alternative outcome (Different; i.e. $R_{1}$ during $S_{2}$ and $R_{2}$ during $S_{1}$ ). An ANOVA with response type (same, different, control) as a factor showed a significant main effect of response type, $F(2,22)=9.77, p=.001, \eta_{p}{ }^{2}=.47, \mathrm{Cl}=[.166 ; .611]$, and planned orthogonal comparisons confirmed that participants' PIT scores were higher for 'same' responses than for both 'different' and 'control' responses, $F(1,11)=10.93, p=.007, \eta_{p}{ }^{2}=$ $.498, \mathrm{Cl}=[.106 ; .679]$ and also that 'different' and 'control' PIT scores did not differ, $F<1$. One-sample t-tests on these scores showed significant difference for Same, $p=.001$, but not for Different, $p=.203$ or Control, $p=.136$. The mean response rates during the pre- 
stimulus periods were $19.1(\mathrm{SEM}=7.3), 19.8(\mathrm{SEM}=8.4)$, and $19.8 \mathrm{rpm}(\mathrm{SEM}=8.1)$, for Same, Different, and Control, respectively. These differences were not statistically significant, $F \mathrm{~s}<1$.

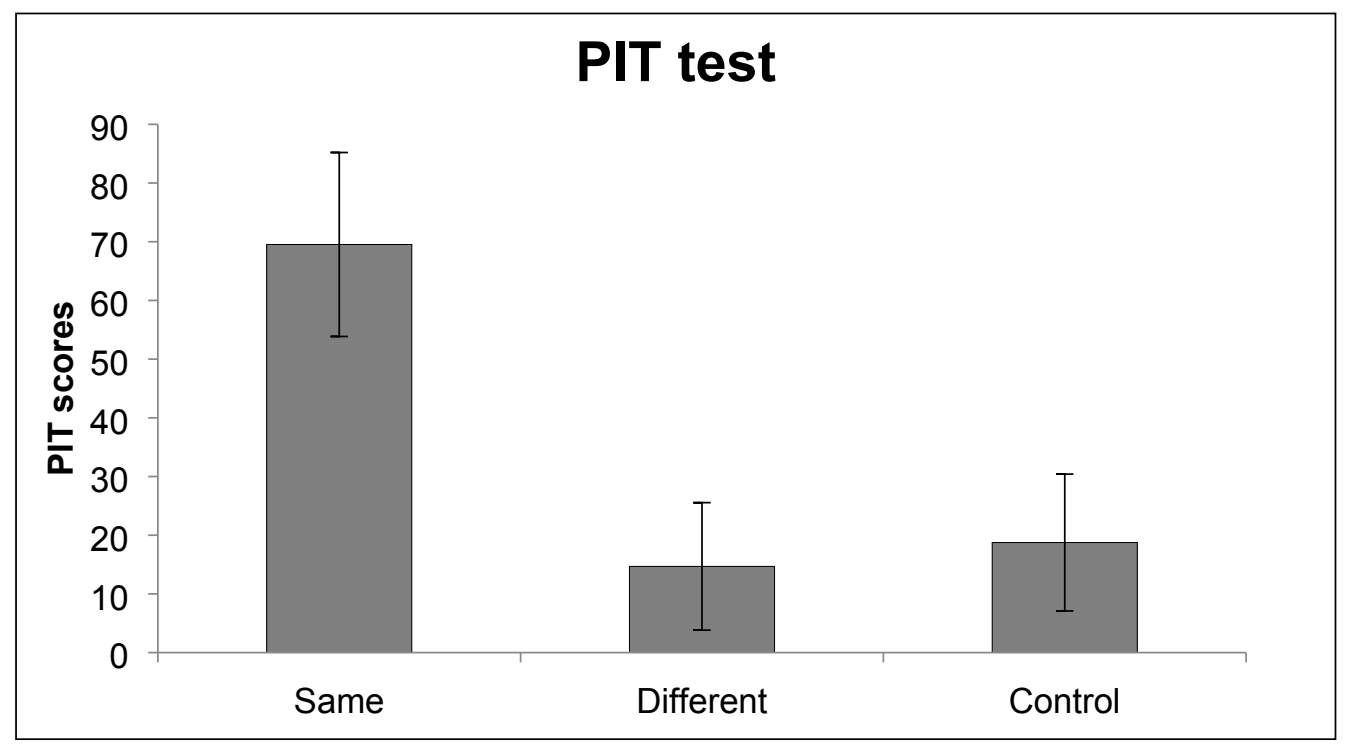

Figure 2. Instrumental responding expressed as PIT scores \pm SEM (CS - pre CS responding) during the stimulus trained with either the same outcome as the instrumental response (Same; $R_{1}$ during $S_{1}$ and $R_{2}$ during $S_{2}$ ), different outcome (Different; $R_{1}$ during $S_{2}$ and $R_{2}$ during $S_{1}$ ), or no outcome (Control; $R_{1}$ and $R_{2}$ during $S_{3}$ ), averaged over the 2 blocks of the PIT test of Experiment 1.

All the participants answered all the questions correctly_very close or right on the expected end of the scale). The mean calculated scores to the questions about $S_{1}, S_{2}$ and $\mathrm{S}_{3}$ were $0.01(\mathrm{SEM}<0.01), 0.02(\mathrm{SEM}=0.01)$, and $0.02(\mathrm{SEM}<0.01)$ respectively.

\section{Experiment 2: Outcome-specific and general PIT}

The results of Experiment 1 confirmed that the task was effective in reproducing the outcome-specific PIT effect in children, using symbolic rewards. Presentations of images that signaled food or drink pictures increased responding, but only if the stimulus 
and the response were trained with the same outcome. In Experiment 2 the design was slightly modified to assess if outcome-specific and general PIT could be found in the same task with child participants (see Table 2). The critical modification was the inclusion of a new S-O relationship $\left(\mathrm{S}_{3}-\mathrm{O}_{3}\right)$. This new stimulus signaled the presentation of an outcome that was not used to reinforce either of the instrumental responses. Because of this, we predicted that $S_{3}$ would produce an elevation of both $R_{1}$ and $R_{2}$, relative to the effect of the control cue that signaled no outcome $\left(S_{4^{-}}\right)$. In addition, and as in Experiment $1, S_{1}$ and $S_{2}$ should produce a selective elevation of the response that produced the same outcome (outcome-specific PIT).

Table 2. Design of Experiment 2.

\begin{tabular}{llll}
\hline Pavlovian Phase & Instrumental Phase & PIT Test & Questions \\
\hline $\mathrm{S}_{1^{-}>\mathrm{O}_{1}}$ & $\mathrm{R}_{1^{-}>\mathrm{O}_{1}}$ & $\mathrm{~S}_{1}: \mathrm{R}_{1}$ ? $\mathrm{R}_{2} ?$ & $\mathrm{~S}_{1}: \mathrm{O}_{1}$ or $\mathrm{O}_{2} ?$ \\
$\mathrm{~S}_{2^{-}>\mathrm{O}_{2}}$ & $\mathrm{R}_{2^{-}>\mathrm{O}_{2}}$ & $\mathrm{~S}_{2}: \mathrm{R}_{1}$ ? $\mathrm{R}_{2} ?$ & $\mathrm{~S}_{2}: \mathrm{O}_{1}$ or $\mathrm{O}_{2} ?$ \\
$\mathrm{~S}_{3^{-}>\mathrm{O}_{3}}$ & & $\mathrm{~S}_{3}: \mathrm{R}_{1}$ ? $\mathrm{R}_{2} ?$ & $\mathrm{~S}_{3}: \mathrm{O}_{1}$ or $\mathrm{O}_{2} ?$ \\
$\mathrm{~S}_{4^{-}}$ & & $\mathrm{S}_{4}: \mathrm{R}_{1}$ ? $\mathrm{R}_{2} ?$ & $\mathrm{~S}_{4}: \mathrm{O}_{1}$ or $\mathrm{O}_{2} ?$ \\
\hline
\end{tabular}

Note: $R_{1}$ and $R_{2}$ refer to keyboard responses; $S_{1}, S_{2}, S_{3}$, and $S_{4}$ refer to neutral cartoon images of children; $\mathrm{O}_{1}, \mathrm{O}_{2}$, and $\mathrm{O}_{3}$ refer to images of pets, - to a blank square.

\section{Method}

\section{Participants}

A total of 37 participants were initially recruited from three local primary schools; however, 11 of these participants performed an incorrect version of the task, and they were immediately excluded from the study. From the remaining 26 , two of them performed at $50 \%$ correct or less in the final Pavlovian assessment (see Data Treatment section). 
These were therefore excluded, leaving a total of twenty-four children participating in the experiment; these were aged between 7 and 11, and comprised 13 males and 11 females.

Ethics statement. Participants' parents or carers gave informed consents for their children to participate in this study, and all the participants gave verbal consent before participating in the task.

\section{Apparatus and materials}

An additional cartoon image was added to the set of images used as Ss in Experiment 1 and the food and drink images were replaced by pictures of pets - 8 puppies, 8 kittens, and 8 bunnies. The stimuli and outcomes were counterbalanced (see supplementary materials). Because of the additional outcome, the rating scale was replaced by a series of questions about the S-O relationships.
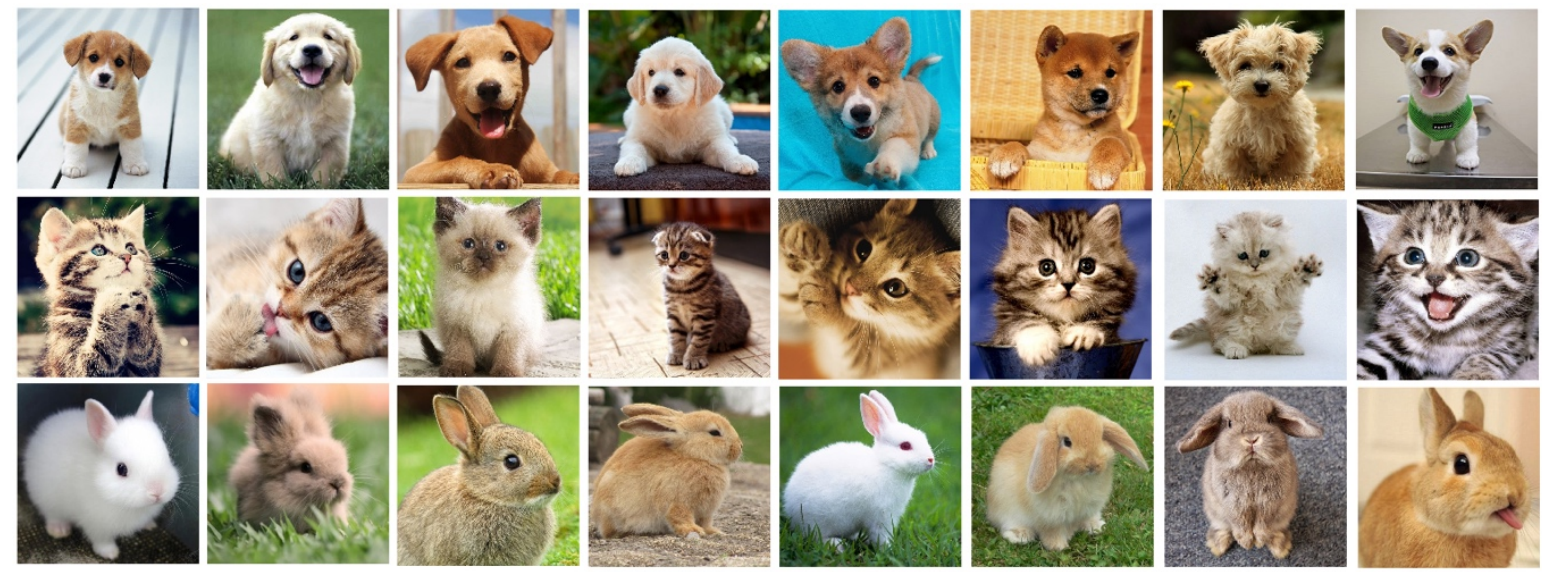

Figure 3. Outcomes used in Experiment 2.

\section{Procedure}

Everything was the same as in Experiment 1 unless otherwise stated.

\section{Pavlovian phase}


Participants read the following instructions:

"Some of these children really want a pet and you are going to help them to get one!

One of the children wants a puppy, another wants a kitten, another wants a bunny and one does not want a pet.

Now you will see the children and the pets they want so you need to remember which child wants each of the pets so you can help them later!

When you are ready press the green button"

The phase was divided into 4 blocks, each of them consisting of two trials of each of $S_{1^{-}}>O_{1}, S_{2^{-}}>O_{2}, S_{3^{-}}>O_{3}$, and $S_{4^{-}}$(8 trials of each type in total).

\section{Instrumental training phase}

Participants read the following instructions:

"Now press the red keys to catch and ! Another friend will be catching the so you do not have to worry about that.

One key will help you to catch and the other . Once you get 30 of each you will give the pets to the children!

Sometimes the keys will not do anything, but just keep pressing! When you are ready press the green button"

One of the keys was trained with $\mathrm{O}_{1}$ and the other with $\mathrm{O}_{2}$. The spaces marked as were filled with the words 'puppies', 'bunnies', or 'kittens', depending on the experimental condition assigned to the participant $\left(\mathrm{O}_{1}\right.$ and $\left.\mathrm{O}_{2}\right)$. The words 'Food' and 
'Drink' in the counters were replaced by 'puppies', 'bunnies', and 'kittens', also depending on the counterbalancing condition.

\section{PIT test}

Participants read the following instructions:

"Now it's time to help the children to get their pets! You can give them pets by pressing the red keys again.

You will not see the pets, but the children will receive them anyway so just keep pressing!

When you are ready press the green button"

The counters were modified as described in the previous phase. The test was divided into 2 blocks, each consisting of 2 trials of each of $S_{1}, S_{2}, S_{3}$, and $S_{4}(4$ trials of each type in total).

\section{Questions}

Participants read the following instructions:

"Now you will see the children again. Can you remember which pets they preferred?

You need to press the numbers 1, 2, 3 or 4 for each of the children and you will see the pets to help you to remember.

When you are ready press the green button"

On each trial the question "What did this child want?" was located on the top of the screen and one of the Ss was presented at the center of the screen. Below the S there were four smaller images $\left(\mathrm{O}_{1}, \mathrm{O}_{2}, \mathrm{O}_{3}\right.$ or the blank square). Different images were 
presented in each trial, $3 \times 3 \mathrm{~cm}$ in size, semi-randomly selected from the group of images used in the previous phases. The corresponding name was written below each image ('Puppy', 'Kitten', 'Bunny', or 'No pet'), and above each image there was a number (1, 2, 3 or 4). Each trial ended when the participants pressed one of the keys. The test was one block comprising 2 trials with each cue $\left(S_{1}, S_{2}, S_{3}\right.$, and $\left.S_{4}\right)$.

\section{Data treatment}

Rates of each response during each stimulus were converted into rpm, and the corresponding preCS response rates subtracted to produce PIT scores, exactly as in Experiment 1 . The data required to demonstrate specific PIT were extracted exactly as in Experiment 1: PIT scores for $R_{1}$ and $R_{2}$ during $S_{1}$ and $S_{2}$ were coded according to whether they were same (when both response and stimulus had signaled the same outcome) or different. Greater same than different scores indicated specific PIT. The measure of general PIT was necessarily a little different, as this refers to a nonspecific elevation of responding during the reward-associated $S_{3}$, compared to the non-reward-associated $S_{4}$ meaning that $R_{1}$ and $R_{2}$ were functionally equivalent for this measure. Thus PIT scores for $R_{1}$ and $R_{2}$ during $S_{3}$ and during $S_{4}$ were pooled; greater scores during $S_{3}$ than $S_{4}$ would indicate general PIT. As in Experiment 1, one-sample two-tailed t-tests were conducted on the PIT scores to assess if they were significantly different than zero. For the "Questions", each correct response was assigned a value of 1 and each incorrect response a value of 0 . The mean values for the questions about each cue were calculated and converted to a scale from 0 to 100 . For the exclusion criterion a single mean for all questions was calculated for each participant, and those participants scoring less than $50 \%$ were excluded from the experiment. This exclusion criterion is similar to that used in a previous PIT task in an adult population (Alarcón \& Bonardi, 2016). Two participants were excluded from this study because they failed to meet this exclusion criterion. One of them answered 
the questions about $S_{1}$ and $S_{3}$ incorrectly, while the other incorrectly answered one question about $S_{1}$, two about $S_{3}$, and one about $S_{4}$. This left a total of 24 participants, who all performed to a high degree of accuracy (see below).

\section{Results}

The instrumental training phase was completed uneventfully, and all participants obtained the 30 outcomes produced by each of the two instrumental responses. The results of the PIT test are presented in Figure 2, which shows, as in Experiment 1, a selective elevation of instrumental responding produced by $S_{1} / S_{2}$, i.e., higher PIT scores for $R_{1}$ than for $R_{2}$ during $S_{1}$, and the reverse pattern in $S_{2}$. Moreover, presentation of $S_{3}(S$ Other) also elevated performance of the two instrumental responses relative to presentations of $\mathrm{S}_{4}$ (S Control). An ANOVA with trial type (same, different, other, control) showed a significant main effect, $F(3,69)=10.1, p<.001, \eta_{p}^{2}=.305 ; \mathrm{Cl}=[.139 ; .412]$. Planned orthogonal comparisons confirmed a significant difference between Same and Different, $F(1,69)=15.28, p<.001, \eta_{p}^{2}=.18, \mathrm{Cl}=[.062 ; .306]$, and also between Other and Control, $F(1,69)=5.74, p=.019, \eta_{p}{ }^{2}=.2, \mathrm{Cl}=[.054 ; .306]$. One-sample t-tests on each of the scores showed significant differences for Same, $p=.004$, but not for Different, $p=.335$, Other, $p=.08$, or Control, $p=.445$. The mean response rates during the prestimulus periods were $3.8($ SEM $=3.0), 3.7($ SEM $=2.7), 3.7($ SEM $=3.0)$, and $6.1 \mathrm{rpm}$ $(\mathrm{SEM}=4.4)$, for Same, Different, Other, and Control, respectively. The same analysis on the pre-CS data showed no significant differences, $F(3,69)=2.14, p=.104$. 


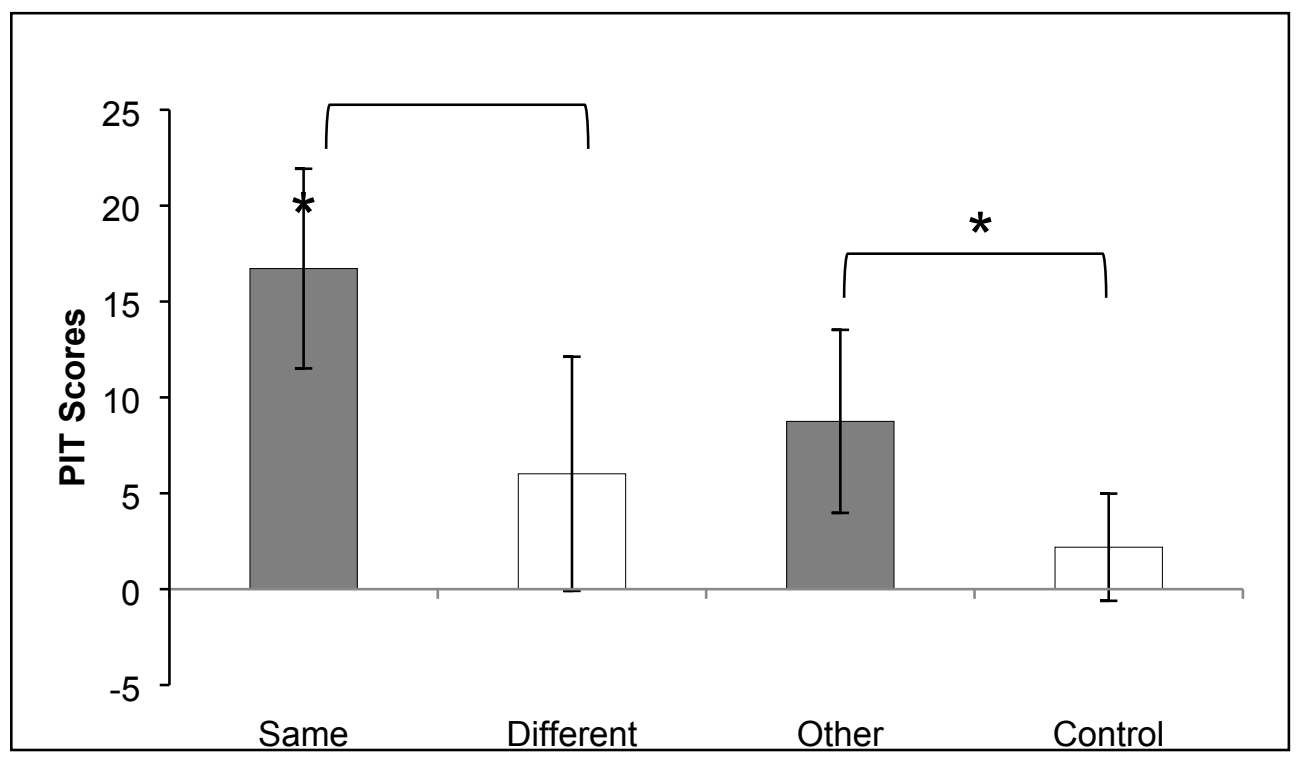

Figure 2. Instrumental performance, expressed as PIT Scores \pm SEM (CS - pre CS responding) of the response paired with the same outcome as the stimulus (Same; $R_{1}$ during $S_{1}$ and $R_{2}$ during $S_{2}$ ), the response paired with the alternative outcome (Different; $R_{1}$ during $S_{2}$ and $R_{2}$ during $S_{1}$ ), and of both responses during the stimulus paired with the third outcome $\mathrm{O}_{3}$ (Other; $R_{1}$ and $R_{2}$ during $S_{3}$ ) or with no outcome (Control; $R_{1}$ and $R_{2}$ during $S_{4}$ ), averaged over the 2 blocks of the PIT test of Experiment 2. Significant differences $(p<0.05)$ are expressed by $\left(^{*}\right)$.

The mean score to the questions about $\mathrm{S}_{1}$ was $97.9\left(\mathrm{SEM}=2.1\right.$ ), for $\mathrm{S}_{2} 97.9$ (SEM $=2.1)$, for $S_{3}$ was $91.7($ SEM $=4.9)$, and for $S_{4}$ was $100($ SEM $=0)$. Statistical analysis showed no significant differences, $F(3,69)=1.53, p=.21$.

\section{General discussion}

The aim of the experiments reported here was to assess if children show evidence of PIT in a computer-based learning task. Experiment 1 focused on determining whether the outcome-specific form of PIT can be observed when a standard PIT task is used. Children were shown different relationships between distinct cartoon images and symbolic rewards (food or drink pictures), or the absence of the rewards. Then the children were 
trained to press two different keys, each rewarded by one of two symbolic outcomes (food or drink pictures). When tested, children showed an elevation of key pressing in the presence of the cartoon images, but only with the key that was trained with the same reward as that signaled by the cartoon image, i.e. outcome-specific PIT. In Experiment 2, a new cartoon image signaling a new outcome, different from those used to reinforce the key presses, was added to the task. At test, children again showed outcome-specific PIT - a selective elevation of key pressing in the presence of the cues that signaled one of the reinforcers. But in addition, in the presence of the new cartoon, the rate of both key presses was increased, relative to the cartoon image $\mathrm{S}_{4}$ that signaled no reward; in other words the children also showed general PIT.

These results are consistent with previous findings on outcome-specific and general PIT in the adult population and non-human animals, and they can be explained by the stimulus-outcome-response (S-O-R) account (cf. Trapold \& Overmier, 1972). According to this account, in the first experiment, each of the cartoon images became capable of activating a representation of either food, drink or nothing. Then each presentation of these cartoons at test evoked the corresponding representation, which biased choice towards the response that also evoked the same representation. Since the pictures of foods and drinks presumably shared a similar motivational value, the selectivity of the effect can only be mediated by the distinct sensory aspects of the pictures. The outcome-specific effect found in Experiment 2 is explained in the same manner: the cartoons evoked a representation of one of the pets, which in turn elicited a response that was trained with the same pet. However, when the sensory properties of the representation evoked by the cartoon did not correspond with those evoked by either of both responses, the cartoon presentation also elevated responding, relative to a stimulus signaling no outcome. In this case, the motivational elements shared between the two 
outcome representations are likely to be responsible for this general elevation of performance.

The outcome-specific PIT effect has been commonly reported in non-human animals and in the adult population but, to our knowledge, this is the first report of the effect in children. Conclusive demonstrations of the general form of PIT, however, are rarer, in part because some researchers have used designs that do not allow us to distinguish between the two forms of PIT - for instance, by training only one cue to predict outcome delivery (e.g., Lovibond \& Colagiuri, 2013; Saddoris, Stamakis \& Carelli, 2011; Talmi, Seymour, Dayan \& Dolan, 2008). Nevertheless, there have been some reports in which both outcome-specific and general forms of PIT have been found in the same task, first with rodents (Corbit \& Balleine, 2005; 2011; Corbit, Fischbach \& Janak, 2016), and later with humans (Nadler, Delgado \& Delamater, 2011; Morris et al., 2015; Quail et al., 2017; Watson et al., 2014).

One important aspect of this report is that outcome-specific and general PIT were both found in the same task, and using symbolic rewards, which has not usually been achieved in the literature (but see Morris et al, 2015; Quail et al., 2017). For instance, Nadler et al. (2011; Experiment 1a) made a first attempt by using a design similar to that used in our Experiment 2, using adults as participants. Although, unlike us, they conducted instrumental training before the Pavlovian phase, they also used symbolic rewards, namely images of a coin, a star, and a key, as outcomes. In their experiment participants showed evidence of outcome-specific PIT but not general PIT. Nadler et al. (2011) argued that the low motivational value of the outcomes could have been responsible for the absence of general PIT, which is thought to be mainly a motivational effect. They made a second attempt in which they replaced the outcome with an image representing money that was given to the participants at the end of the experiment (Experiment $1 \mathrm{~b}$ ), but this 
also failed to reveal general PIT. Finally, Nadler et al. (2011) took a different approach and they used a computer game, based on a task developed by Paredes-Olay et al. (2002), in which participants had to defend a country by shooting (by pressing keys) planes and ships (R-O relationships). The results of this experiment successfully showed both outcome-specific and general PIT, although it is not clear which aspects of this new task was responsible for this effect. It is likely that in our task the images of foods, drinks, and pets had a higher motivational value than those used by Nadler et al. (2011), since they might have evoked a representation or memory of the actual foods/drinks directly. It is possible, then, that using natural rewards as outcomes might result in an even larger effect, although to our knowledge there has been no direct comparison between the PIT effect produced by symbolic outcomes and natural rewards. An additional factor might be the age of the participants - the images might have greater motivational value for the children than for adults.

Because this task was created for children, the cover story and instructions were aimed to keep the participants engaged, and not identical to those used in other PIT tasks. Adult PIT experiments commonly use images such as fractals or geometrical figures (e.g., Alarcón \& Bonardi, 2016; Watson et al., 2014) that are simply followed by an outcome. In contrast, in the experiments reported here, although there was still a clear predictive relationship between the different children and the various outcomes - the conditions required to produce Pavlovian conditioning - the participants were told that the cartoon images of children that served as CSs obtained the outcomes that followed them. It could be argued that this feature might have led participants to perform instrumental actions at test due to a reasoning process rather than purely based on the Pavlovian associations. For example, in Experiment 2 the participants were instructed at test to respond to "get the children their pets", and so they could have solved the task by means of a reasoning 
process - seeing the child who wanted a rabbit made them press the key that produced rabbits. We think this is unlikely, however. First, although this logic could in principle generate the specific PIT effect observed in Experiment 2, it is less clear how it would generate the general PIT effect, where participants were pressing keys to obtain pets that were not those wanted by the child CS presented. Second, it cannot easily explain the results of Experiment 1, in which at test the participants were simply told to press for the food and drink, without any implication that these would be received by the child CSs. Another case in which the instructions might have confounded our interpretations is in Experiment 2, in which participants were told at the beginning of the task that one of the characters "does not want a pet" $\left(\mathrm{S}_{4}\right.$, the control cue for general PIT). Due to this, reasoning should have led participants to suppress responding when this cue was presented at test, making $\mathrm{S}_{4}$ a less than ideal control cue. However, if this were correct then this cue should have reduced responding relative to the baseline (pre CS), but numerically this was not what we found (although there might have been a floor effect that did not allow us to detect any possible suppression).

But even if we reject these possibilities, we still cannot state with any certainty that the PIT we observed was due to associative learning processes rather than some form of reasoning. However, this is true for most human PIT tasks - and moreover the involvement of reasoning does not preclude the formation and contribution of Pavlovian associations to PIT. Some authors have even argued that PIT is essentially propositional in nature (e.g., Seabrook, Hogarth \& Mitchell, 2016), and that humans make a deliberate choice at test based on the information provided by the Pavlovian cues. In this regard, one could argue that reasoning might be less likely in the younger children, meaning the present findings could in principle bear on this debate. The purpose of our study, however, was not to dwell on the nature of PIT, but to provide a simple tool to study the effect of Pavlovian cues on 
behavior. The PIT effects found in both experiments required learning about the relationships trained in the Pavlovian phase as well about the instrumental associations, and they are comparable to those found in animal and adult PIT studies. Nevertheless, future versions of this task could use instructions more similar to those in adult studies in order to help rule out these potential alternative explanations.

We believe that our task could be a useful tool for assessing the effect on behavior caused by different types of discrete and environmental cues - which is especially important early in life. These cues can develop associations with consequences that are not always desirable, and might become capable of automatically triggering maladaptive behaviors, such as binge eating, drinking, gambling, etc. For example, in modern society there is an overabundance of food, especially food of high calorie content, and children are constantly bombarded by marketing oriented to affect their consumption and preferences, through their influence on families' purchases and their own growing purchasing power, and their choices and eating behavior (Andreyeva, Kelly \& Harris, 2011; Boyland \& Halford, 2013; Folkvord et al., 2016; Uribe \& Fuentes-García, 2015). Some advertising strategies have used popular cartoon characters as brand images to influence children's preferences (Boyland, Harrold, Kirkham \& Halford, 2012; Connor, 2006; Story \& French, 2004; Weber, Story \& Harnack, 2006). Thus better understanding the scope of such stimuli to influence behavior (either through directly promoting product consumption or via a broader behavioral effect) can be useful to protect our children from the negative impact of advertising.

Another aspect of the task worthy of comment is the use of symbolic outcomes rather than real foods and drinks. Symbolic outcomes of the type used here can be regarded as conditioned reinforcers, that is, stimuli that possess reinforcing properties based on their associative history with real outcomes. It is therefore an empirical question 
as to whether similar results would be obtained with outcomes that participants could consume. But given that both the outcome-specific and general forms of PIT have been replicated in adults using both symbolic and real outcomes, indicating that the underlying learning processes of these tasks are equivalent, it seems unlikely that children would differ in this regard. Moreover, the use of symbolic outcomes has advantages, allowing better control over delivery of the outcomes and the time for which participants can access them (see Alarcón, Bonardi \& Delamater, 2019). However, in some cases the use of real outcomes becomes more important. For instance, some experiments have examined whether outcome-specific PIT persists after the motivational value of one of the outcomes has been reduced, and while some experiments using symbolic rewards have found a reduction in PIT (Allman, DeLeon, Cataldo, Holland, \& Johnson, 2010), others using real outcomes have found PIT to be unaffected by outcome devaluation (Watson et al., 2014). Although the idea that these differences were caused by the use of symbolic or real outcomes has been proposed (Eder \& Dignath, 2015), this is not entirely clear and systematic research exploring differences between the two types of outcomes is required.

Another interesting issue is that the magnitude of PIT might vary depending on the characteristics of the populations being studied. For instance, it has been shown that obese people pay more attention to food-related cues than normal-weight participants (Boutelle \& Bouton, 2015; Castellanos et al., 2009; Hendrikse et al., 2015; Werthmann et al., 2011). It might be that obese people are also more sensitive to the effect of these cues on food-seeking behavior. A recent study found that the PIT effect observed in overweight participants was larger than that found in normal-weight participants (Lehner et al., 2017), although obese people showed a smaller effect than overweight participants. It is not clear why these cues might affect overweight and obese people differentially; thus additional 
research is needed to better understand how these cues affect behavior, and with which other factors they interact.

Overall, we have developed a task to study PIT effects in the child population something which, to our knowledge, has not been done before. This task allows us to observe both outcome-specific and general forms of PIT. Importantly, this was achieved by using symbolic rather than natural rewards, which presents a series of practical advantages. We believe that the results reported here are a contribution to the current knowledge about PIT, and how it extends to the child population. This will facilitate future research into the maladaptive behavior that is observed in adults in response to rewardrelated stimuli, when it appears at an earlier stage of development. 


\section{References}

Alarcón, D., \& Bonardi, C. (2016). The effect of conditioned inhibition on the specific Pavlovianinstrumental transfer effect. Journal of Experimental Psychology: Animal Learning and Cognition, 42, 82-94.

Alarcón, D. E., Bonardi, C., \& Delamater, A. R. (2018). Associative mechanisms involved in specific Pavlovian-to-instrumental transfer (PIT) in human learning tasks. The Quarterly Journal of Experimental Psychology, 1-55.

Alarcón, D. E., \& Delamater, A. R. (2019). Outcome-specific Pavlovian-to-instrumental transfer (PIT) with alcohol cues and its extinction. Alcohol, 76, 131-146.

Andreyeva, T., Kelly, I. R., \& Harris, J. L. (2011). Exposure to food advertising on television: Associations with children's fast food and soft drink consumption and obesity.

Economics and Human Biology, 9(3), 221-233.

https://doi.org/10.1016/j.ehb.2011.02.004

Bindra, D. (1968). Neuropsychological interpretation of the effects of drive and incentivemotivation on general activity and instrumental behavior. Psychological Review, 75(1), 1-22. https://doi.org/10.1037/h0025306

Boakes, R. A. (1979). Interactions between type I and type II processes involving positive reinforcement. Mechanisms of learning and motivation: A memorial volume to Jerzy Konorski, 233-268.

Boutelle, K. N., \& Bouton, M. E. (2015). Implications of learning theory for developing programs to decrease overeating. Appetite, 93, 62-74. https://doi.org/10.1016/j.appet.2015.05.013

Boyland, E. J., \& Halford, J. C. G. (2013). Television advertising and branding. Effects on eating behaviour and food preferences in children. Appetite, 62, 236-241. https://doi.org/10.1016/j.appet.2012.01.032

Boyland, E. J., Harrold, J. A., Kirkham, T. C., \& Halford, J. C. G. (2012). Persuasive techniques used in television advertisements to market foods to UK children. Appetite, 58(2), 658664. https://doi.org/10.1016/j.appet.2011.11.017

Castellanos, E. H., Charboneau, E., Dietrich, M. S., Park, S., Bradley, B. P., Mogg, K., \& Cowan, R. L. (2009). Obese adults have visual attention bias for food cue images: Evidence for altered reward system function. International Journal of Obesity, 33(9), 1063-1073. https://doi.org/10.1038/ijo.2009.138

Colagiuri, B., \& Lovibond, P. F. (2015). How food cues can enhance and inhibit motivation to obtain and consume food. Appetite, 84, 79-87. https://doi.org/10.1016/j.appet.2014.09.023

Colwill, R. M., \& Rescorla, R. A. (1988). Associations between the discriminative stimulus and the reinforcer in instrumental learning. Journal of Experimental Psychology: Animal Behavior Processes, 14(2), 155-164. https://doi.org/10.1037/0097-7403.14.2.155 
Connor, S. M. (2006). Food-Related Advertising on Preschool Television: Building Brand Recognition in Young Viewers. Pediatrics, 118(4), 1478-1485.

https://doi.org/10.1542/peds.2005-2837

Corbit, L. H., \& Balleine, B. W. (2005). Double Dissociation of Basolateral and Central Amygdala Lesions on the General and Outcome-Specific Forms of PavlovianInstrumental Transfer. Journal of Neuroscience, 25(4), 962-970. https://doi.org/10.1523/JNEUROSCI.4507-04.2005

Corbit, L. H., \& Balleine, B. W. (2011). The general and outcome-specific forms of Pavlovianinstrumental transfer are differentially mediated by the nucleus accumbens core and shell. The Journal of Neuroscience: The Official Journal of the Society for Neuroscience, 31(33), 11786-11794. https://doi.org/10.1523/JNEUROSCI.271111.2011

Corbit, L. H., Fischbach, S. C., \& Janak, P. H. (2016). Nucleus accumbens core and shell are differentially involved in general and outcome-specific forms of Pavlovian-instrumental transfer with alcohol and sucrose rewards. European Journal of Neuroscience, 43(9), 1229-1236. https://doi.org/10.1111/ejn.13235

Craske, M. G., Wolitzky-Taylor, K. B., Mineka, S., Zinbarg, R., Waters, A. M., VrshekSchallhorn, S., ... Ornitz, E. (2012). Elevated responding to safe conditions as a specific risk factor for anxiety versus depressive disorders: Evidence from a longitudinal investigation. Journal of Abnormal Psychology, 121(2), 315-324. https://doi.org/10.1037/a0025738

Crone, E. A., \& van der Molen, M. W. (2004). Developmental changes in real life decisión making: performance on a gambling task previously shown to depend on the ventromedial prefrontal cortex. Developmental Neuropsychology, 25(3), 251-279.

Crone, E. A., Richard Jennings, J., \& Van Der Molen, M. W. (2004). Developmental change in feedback processing as reflected by phasic heart rate changes. Developmental Psychology, 40(6), 1228-1238. https://doi.org/10.1037/0012-1649.40.6.1228

De Tommaso, M., Mastropasqua, T., Turatto, M., Kosheleff, A. R., Araki, J., Hsueh, J., ... Ehrman, R. N. (2017). Testing pavlovian conditioning within the transfer of control paradigm . European Journal of Neuroscience, 8(3), 288-295. https://doi.org/10.1162/jocn_a_00945

Deckelbaum, R. J., \& Williams, C. L. (2001). Childhood obesity: the health issue. Obesity, 9(S11).

Delamater, A. R. (1996). Effects of several extinction treatments upon the integrity of Pavlovian stimulus-outcome associations. Animal Learning \& Behavior, 24(4), 437-449. https://doi.org/10.3758/BF03199015

Dickinson, A., \& Balleine, B. W. (2002). The role of learning in the operation of motivation systems. In H. Pashler \& C. R. Gallistel (Eds.), Steven's handbook of experimental psychology: Vol. 3. Learning, motivation, and emotion (3rd ed., pp. 497-533). New York: John Wiley \& Sons.

Eppinger, B., Mock, B., \& Kray, J. (2009). Developmental differences in learning and error processing: Evidence from ERPs. Psychophysiology, 46(5), 1043-1053.

https://doi.org/10.1111/j.1469-8986.2009.00838.x 
Folkvord, F., Anschütz, D. J., \& Buijzen, M. (2016). The association between BMI development among young children and (un)healthy food choices in response to food advertisements: A longitudinal study. International Journal of Behavioral Nutrition and Physical Activity, 13(1), 1-7. https://doi.org/10.1186/s12966-016-0340-7

Garbusow, M., Schad, D. J., Sebold, M., Friedel, E., Bernhardt, N., Koch, S. P., ... Heinz, A. (2016). Pavlovian-to-instrumental transfer effects in the nucleus accumbens relate to relapse in alcohol dependence. Addiction Biology, 21(3), 719-731. https://doi.org/10.1111/adb.12243

Glenn, C. R., Klein, D. N., Lissek, S., Britton, J. C., Pine, D. S., \& Hajcak, G. (2012). The development of fear learning and generalization in 8-13 year-olds. Developmental Psychobiology, 54(7), 675-684. https://doi.org/10.1002/dev.20616

Hendrikse, J. J., Cachia, R. L., Kothe, E. J., Mcphie, S., Skouteris, H., \& Hayden, M. J. (2015). Attentional biases for food cues in overweight and individuals with obesity: A systematic review of the literature. Obesity Reviews, 16(5), 424-432. https://doi.org/10.1111/obr.12265

Holmes, N. M., Marchand, A. R., \& Coutureau, E. (2010). Pavlovian to instrumental transfer: A neurobehavioural perspective. Neuroscience and Biobehavioral Reviews, 34(8), 12771295. https://doi.org/10.1016/j.neubiorev.2010.03.007

Jansen, A., Theunissen, N., Slechten, K., Nederkoorn, C., Boon, B., Mulkens, S., \& Roefs, A. (2003). Overweight children overeat after exposure to food cues. Eating Behaviors, 4(2), 197-209. https://doi.org/10.1016/S1471-0153(03)00011-4

Jovanovic, T., Nylocks, K. M., Gamwell, K. L., Smith, A., Davis, T. A., Norrholm, S. D., \& Bradley, B. (2014). Development of fear acquisition and extinction in children: Effects of age and anxiety. Neurobiology of Learning and Memory, 113, 135-142. https://doi.org/10.1016/j.nlm.2013.10.016

Konorski, J. (1967). Integrative activity of the brain: An interdisciplinary approach. Chicago: University of Chicago Press.

Koolschijn, P. C. M. P., Schel, M. A., de Rooij, M., Rombouts, S. A. R. B., \& Crone, E. A. (2011). A Three-Year Longitudinal Functional Magnetic Resonance Imaging Study of Performance Monitoring and Test-Retest Reliability from Childhood to Early Adulthood. Journal of Neuroscience, 31(11), 4204-4212. https://doi.org/10.1523/JNEUROSCI.6415-10.2011

Kruse, J. M., Overmier, J. B., Konz, W. A., \& Rokke, E. (1983). Pavlovian conditioned stimulus effects upon instrumental choice behavior are reinforcer specific. Learning and Motivation, 14(2), 165-181. https://doi.org/10.1016/0023-9690(83)90004-8

Lamb, R. J., Ginsburg, B. C., \& Schindler, C. W. (2017). Conditioned Stimulus Form Does Not Explain Failures to See Pavlovian-Instrumental-Transfer With Ethanol-Paired Conditioned Stimuli. Alcoholism: Clinical and Experimental Research, 41(5), 1063-1071. https://doi.org/10.1111/acer.13376

Lau, J. Y., Britton, J. C., Nelson, E. E., Angold, A., Ernst, M., Goldwin, M., ... Pine, D. S. (2011). Distinct neural signatures of threat learning in adolescents and adults. Proceedings of the National Academy of Sciences, 108(11), 4500-4505.

https://doi.org/10.1073/pnas.1005494108 
Lehner, R., Balsters, J. H., Herger, A., Hare, T. A., \& Wenderoth, N. (2017). Monetary, food, and social rewards induce similar pavlovian-to-instrumental transfer effects. Frontiers in Behavioral Neuroscience, 10. https://doi.org/10.3389/fnbeh.2016.00247

Liberman, L. C., Lipp, O. V., Spence, S. H., \& March, S. (2006). Evidence for retarded extinction of aversive learning in anxious children. Behaviour Research and Therapy, 44(10), 1491-1502. https://doi.org/10.1016/j.brat.2005.11.004

Lovibond, P. F., \& Colagiuri, B. (2013). Facilitation of voluntary goal-directed action by reward cues. Psychological Science, 24(10), 2030-2037. https://doi.org/10.1177/0956797613484043

Morris, R. W., Quail, S., Griffiths, K. R., Green, M. J., \& Balleine, B. W. (2015). Corticostriatal control of goal-directed action is impaired in schizophrenia. Biological Psychiatry, 77(2), 187-195. https://doi.org/10.1016/j.biopsych.2014.06.005

Nadler, N., Delgado, M. R., \& Delamater, A. R. (2011). Pavlovian to instrumental transfer of control in a human learning task. Emotion, 11(5), 1112-1123. https://doi.org/10.1037/a0022760

Nederkoorn, C., Smulders, F. T. Y., \& Jansen, A. (2000). Cephalic phase responses, craving and food intake in normal subjects. Appetite, 35(1), 45-55. https://doi.org/10.1006/appe.2000.0328

Neumann, D. L., Waters, A. M., \& Westbury, H. R. (2008). The use of an unpleasant sound as the unconditional stimulus in aversive Pavlovian conditioning experiments that involve children and adolescent participants. Behavior Research Methods, 40(2), 622-625. https://doi.org/10.3758/BRM.40.2.622

Paredes-Olay, C., Abad, M. J. F., Gámez, M., \& Rosas, J. M. (2002). Transfer of control between causal predictive judgments and instrumental responding. Animal Learning \& Behavior, 30(3), 239-248. https://doi.org/10.3758/BF03192833

Peirce, J. W. (2007). PsychoPy - Psychophysics software in Python. Journal of Neuroscience Methods, 162, 8-13.

Quail, S. L., Morris, R. W., \& Balleine, B. W. (2017). Stress associated changes in Pavlovianinstrumental transfer in humans. The Quarterly Journal of Experimental Psychology, 70(4), 675-685. https://doi.org/10.1080/17470218.2016.1149198

Quezada, V., Alarcón, D., Miguez, G., \& Betancourt, R. (2009). Aumento de la conducta operante tras la presentación de estímulos condicionados asociados al efecto del etanol. Revista de Psicología, 18(2).

Rescorla, R. A., \& Soloman, R. L. (1967). Two-process learning theory: Relationships between Pavlovian conditioning and instrumental learning. Psychological Review, 74(3), 713713. https://doi.org/10.1037/h0021465

Robinson, T. E., \& Berridge, K. C. (1993). The neural basis of drug craving: An incentivesensitization theory of addiction. Brain Research Reviews, 18(3), 247-291. https://doi.org/10.1016/0165-0173(93)90013-P

Rodin, J. (1985). Insulin levels, hunger, and food intake: an example of feedback loops in body weight regulation. Health Psychology: Official Journal of the Division of Health Psychology, American Psychological Association, 4(1), 1-24. https://doi.org/10.1037/0278-6133.4.1.1 
Saddoris, M. P., Stamatakis, A., \& Carelli, R. M. (2011). Neural correlates of Pavlovian-toinstrumental transfer in the nucleus accumbens shell are selectively potentiated following cocaine self-administration. European Journal of Neuroscience, 33(12), 22742287. https://doi.org/10.1111/j.1460-9568.2011.07683.x

Shephard, E., Jackson, G. M., \& Groom, M. J. (2014). Learning and altering behaviours by reinforcement: Neurocognitive differences between children and adults. Developmental Cognitive Neuroscience, 7, 94-105. https://doi.org/10.1016/j.dcn.2013.12.001

Story, M., \& French, S. (2004). Food Advertising and Marketing Directed at Children's and Adolescents in the US. The International Journal of Behavioral Nutrition and Physical Activity, 1, 1-17. https://doi.org/10.1186/1479-5868-1-3

Talmi, D., Seymour, B., Dayan, P., \& Dolan, R. J. (2008). Human Pavlovian Instrumental Transfer. Journal of Neuroscience, 28(2), 360-368. https://doi.org/10.1523/JNEUROSCI.4028-07.2008

Trapold, M. A., \& Overmier, J. B. (1972). The second process in instrumental learning. In A. H. Black \& W. F. Prokasy (Eds.), Classical conditioning II: Current research and theory (pp. 427-452). New York, NY: Appleton-Century-Crofts.

Uribe, R., \& Fuentes-García, A. (2015). The effects of TV unhealthy food brand placement on children. Its separate and joint effect with advertising. Appetite, 91, 165-172. https://doi.org/10.1016/j.appet.2015.03.030

Wardle, J. (1990). Conditioning processes and cue exposure in the modification of excessive eating. Addictive Behaviors, 15(4), 387-393. https://doi.org/10.1016/03064603(90)90047-2

Waters, A. M., Henry, J., \& Neumann, D. L. (2009). Aversive Pavlovian Conditioning in Childhood Anxiety Disorders: Impaired Response Inhibition and Resistance to Extinction. Journal of Abnormal Psychology, 118(2), 311-321. https://doi.org/10.1037/a0015635

Waters, A., Theresiana, C., Neumann, D., \& Craske, M. (2017). Developmental differences in aversive conditioning, extinction, and reinstatement: A study with children, adolescents, and adults. Journal of Experimental Child Psychology, 159, 263-278. https://doi.org/10.1016/j.jecp.2017.02.012

Watson, P., Wiers, R. W., Hommel, B., \& De Wit, S. (2014). Working for food you don't desire. Cues interfere with goal-directed food-seeking. Appetite, 79, 139-148. https://doi.org/10.1016/j.appet.2014.04.005

Weber, K., Story, M., \& Harnack, L. (2006). Internet Food Marketing Strategies Aimed at Children and Adolescents: A Content Analysis of Food and Beverage Brand Web Sites. Journal of the American Dietetic Association, 106(9), 1463-1466. https://doi.org/10.1016/j.jada.2006.06.014

Werthmann, J., Roefs, A., Nederkoorn, C., Mogg, K., Bradley, B. P., \& Jansen, A. (2011). Can(not) Take my Eyes off it: Attention Bias for Food in Overweight Participants. Health Psychology, 30(5), 561-569. https://doi.org/10.1037/a0024291 

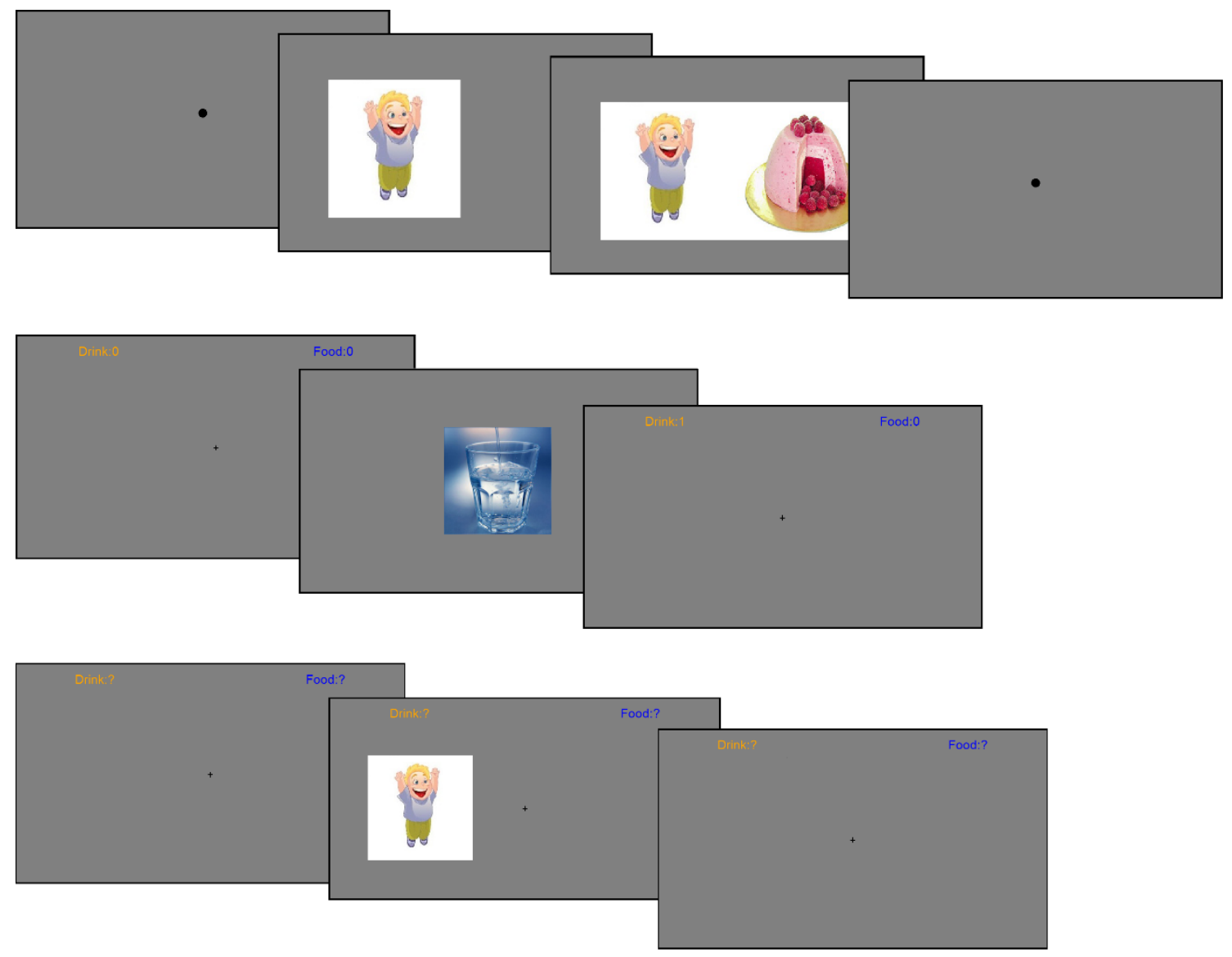

Supplemental Figure 1. An example of the sequence of trials. Pavlovian phase (top panel): a fixation dot $(2 \mathrm{sec})$, followed by the stimulus $(2 \mathrm{sec})$, and then the stimulus and the outcome ( $2 \mathrm{sec}$ ), and then the fixation dot ( $2 \mathrm{sec}$; beginning of a new trial). Instrumental phase (middle panel): a fixation cross replaced by the corresponding outcome $(0.8 \mathrm{sec})$ when one of the keys was pressed according to a variable ratio 3 schedule. The counters (Drink and Food) increased by 1 for each outcome presented. PIT test (bottom panel): the fixation cross was permanently on the center of the screen, and the stimuli were presented at either side of the cross. The counters (Drink and Food) never increased. 

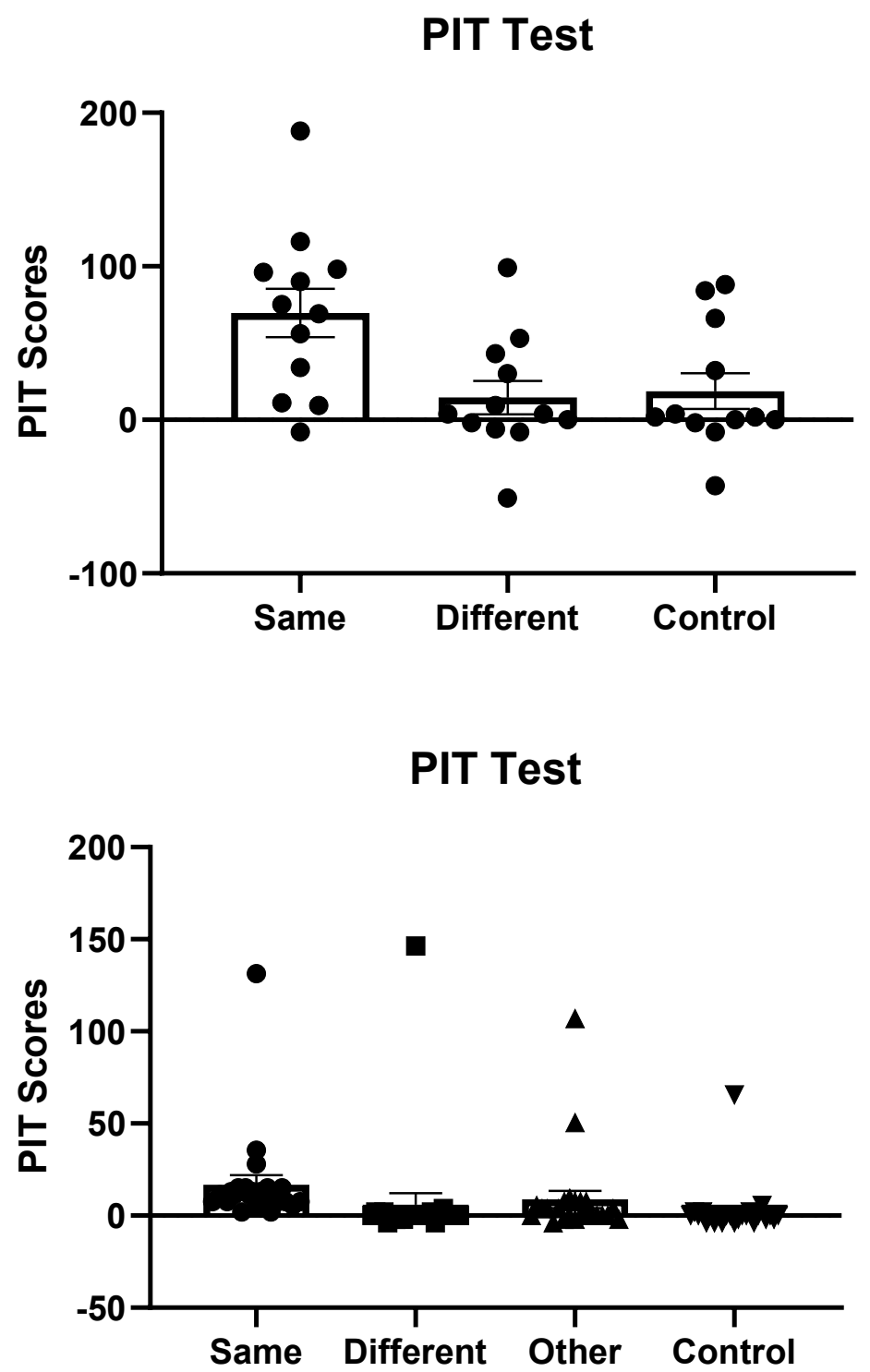


\begin{tabular}{|c|c|c|c|c|}
\hline & & $S_{1}$ & $S_{2}$ & $\mathrm{~S}_{3}$ \\
\hline \multirow{6}{*}{$\begin{array}{c}\mathrm{O}_{1}=\text { Food and } \\
\mathrm{O}_{2}=\text { Drink }\end{array}$} & C1 & 1 & 2 & 3 \\
\hline & $\mathrm{C} 2$ & 1 & 3 & 2 \\
\hline & C3 & 2 & 1 & 3 \\
\hline & C4 & 2 & 3 & 1 \\
\hline & C5 & 3 & 1 & 2 \\
\hline & C6 & 3 & 2 & 1 \\
\hline \multirow{6}{*}{$\begin{array}{c}\mathrm{O}_{1}=\text { Drink and } \\
\mathrm{O}_{2}=\text { Food }\end{array}$} & C7 & 1 & 2 & 3 \\
\hline & C8 & 1 & 3 & 2 \\
\hline & $\mathrm{Cg}$ & 2 & 1 & 3 \\
\hline & C10 & 2 & 3 & 1 \\
\hline & C11 & 3 & 1 & 2 \\
\hline & C12 & 3 & 2 & 1 \\
\hline
\end{tabular}

Supplementary Table 1. Counterbalancing conditions used in Experiment 1. Rows C1-C12 represents each of the 12 conditions. $\mathrm{S}_{1}, \mathrm{~S}_{2}$, and $\mathrm{S}_{3}$ represents the CS paired with $\mathrm{O}_{1}, \mathrm{O}_{2}$ and no-outcome, respectively. Numbers from 1 to 3 represent the physical cartoon images used as CSs. For C1-C6 images of food were used as $\mathrm{O}_{1}$ and images of drinks as $\mathrm{O}_{2}$, and the reverse for $\mathrm{C} 7-\mathrm{C} 12$. 


\begin{tabular}{|c|c|c|c|c|c|c|}
\hline & & & $S_{1}$ & $S_{2}$ & $\mathrm{~S}_{3}$ & $\mathrm{~S}_{4}$ \\
\hline \multirow{4}{*}{$\begin{array}{c}\mathrm{O}_{1}=\text { Kitten and } \\
\mathrm{O}_{2}=\text { Bunny }\end{array}$} & \multirow{8}{*}{$\mathrm{O}_{3}=$ Puppy } & C1 & 1 & 2 & 3 & 4 \\
\hline & & $\mathrm{C} 2$ & 2 & 1 & 4 & 3 \\
\hline & & C3 & 3 & 4 & 1 & 2 \\
\hline & & C4 & 4 & 3 & 2 & 1 \\
\hline \multirow{4}{*}{$\begin{array}{c}\mathrm{O}_{1}=\text { Bunny and } \\
\mathrm{O}_{2}=\text { Kitten }\end{array}$} & & C5 & 1 & 2 & 4 & 3 \\
\hline & & $\mathrm{C} 6$ & 2 & 1 & 3 & 4 \\
\hline & & C7 & 3 & 4 & 2 & 1 \\
\hline & & C8 & 4 & 3 & 1 & 2 \\
\hline \multirow{4}{*}{$\begin{array}{c}\mathrm{O}_{1}=\text { Bunny and } \\
\mathrm{O}_{2}=\text { Puppy }\end{array}$} & \multirow{8}{*}{$\mathrm{O}_{3}=$ Kitten } & $\mathrm{C9}$ & 1 & 2 & 3 & 4 \\
\hline & & $\mathrm{C} 10$ & 2 & 1 & 4 & 3 \\
\hline & & C11 & 3 & 4 & 1 & 2 \\
\hline & & $\mathrm{C} 12$ & 4 & 3 & 2 & 1 \\
\hline \multirow{4}{*}{$\begin{array}{c}\mathrm{O}_{1}=\text { Puppy and } \\
\mathrm{O}_{2}=\text { Bunny }\end{array}$} & & C13 & 1 & 2 & 4 & 3 \\
\hline & & C14 & 2 & 1 & 3 & 4 \\
\hline & & C15 & 3 & 4 & 2 & 1 \\
\hline & & $\mathrm{C} 16$ & 4 & 3 & 1 & 2 \\
\hline \multirow{4}{*}{$\begin{array}{c}\mathrm{O}_{1}=\text { Puppy and } \\
\mathrm{O}_{2}=\text { Kitten }\end{array}$} & \multirow{8}{*}{$\mathrm{O}_{3}=$ Bunny } & $\mathrm{C} 17$ & 1 & 2 & 3 & 4 \\
\hline & & C18 & 2 & 1 & 4 & 3 \\
\hline & & C19 & 3 & 4 & 1 & 2 \\
\hline & & C20 & 4 & 3 & 2 & 1 \\
\hline \multirow{4}{*}{$\begin{array}{c}\mathrm{O}_{1}=\text { Kitten and } \\
\mathrm{O}_{2}=\text { Puppy }\end{array}$} & & $\mathrm{C} 21$ & 1 & 2 & 4 & 3 \\
\hline & & $\mathrm{C} 22$ & 2 & 1 & 3 & 4 \\
\hline & & C23 & 3 & 4 & 2 & 1 \\
\hline & & C24 & 4 & 3 & 1 & 2 \\
\hline
\end{tabular}

Supplementary Table 2. Counterbalancing conditions used in Experiment 2. Rows C1-C24 represents each of the 24 conditions. $S_{1}, S_{2}, S_{3}$, and $S_{4}$ represents the CS paired with $\mathrm{O}_{1}$, $\mathrm{O}_{2}, \mathrm{O}_{3}$, and no-outcome, respectively. Numbers from 1-4 represent the physical cartoon images used as CSs. The left columns of the table represents the identity of $\mathrm{O}_{1}, \mathrm{O}_{2}$ and $\mathrm{O}_{3}$ for each of the conditions. 